\title{
Development of Advanced Radiation Resistant ODS Steel for Fast Reactor System Applications
}

\author{
Tae Kyu Kim*, Sanghoon Noh, Suk Hoon Kang, Hyun Ju Jin, Ga Eon Kim \\ Nuclear Materials Development Division, Korea Atomic Energy Research Institute, Daejeon, Republic of Korea \\ Email: " $\underline{\text { tkkim2@ } @ \text { kaeri.re.kr }}$
}

Received 12 August 2015; accepted 15 October 2015; published 22 October 2015

\begin{abstract}
A sodium-cooled fast reactor (SFR) is being developed at the Korea Atomic Energy Research Institute (KAERI). As in-core structural material for a SFR, advanced radiation resistant ODS steel (ARROS) has been developed. This paper summarizes the current status of ARROS development regarding an ODS steel composition, fabrication technology of ODS steel structural components and key joining technologies of ODS steel structural components.
\end{abstract}

\section{Keywords}

SFR, ODS, ARROS, Cladding Tube, Joining

\section{Introduction}

A sodium-cooled fast reactor (SFR) is being developed at the Korea Atomic Research Institute (KAERI) with a view to economics, safety, reliability, and sustainability [1]. Ferritic/Martensitic (F/M) steels are being primarily considered as materials for the cladding tubes of the SFR due to their excellent irradiation resistance to a void swelling, but are well known to exhibit an abrupt loss of creep strengths at temperatures above $600^{\circ} \mathrm{C}$. For this reason, advanced steel with enhanced mechanical properties at high temperatures has become to be necessary to use at operation temperatures above $600^{\circ} \mathrm{C}[1]$.

Oxide dispersion strengthened (ODS) steels have drawn wide attention as a promising candidate in-core structural materials due to their superior high temperature creep strength and good irradiation resistance to a void swelling under a neutron irradiation environment [2]. Nano-sized oxide particles with a high number density may act as pinning points to dislocation movement or sinks for irradiation induced defects [3]. Hence, advanced ODS steels are being developed as in-core structural materials such as a cladding tube of a commercial SFR in the future.

R \& D on ODS steels consists of mainly 3 tasks; (1) ODS steel composition, (2) fabrication technology of ODS steel cladding tube, and joining technology of ODS steel cladding tube. Extensive studies have been made on the ODS steel R \& D. As a result, advanced ODS steel has been developed, and this material was named as

\footnotetext{
${ }^{*}$ Corresponding author.
} 
the advanced radiation resistant ODS steel $\left(\mathrm{ARROS}^{\mathrm{TM}}\right)$. Representative composition of the ARROS is (in wt\%) Fe-10Cr-1Mo-0.5Mn-0.1V-0.25Ti- $0.35 \mathrm{Y}_{2} \mathrm{O}_{3}$. This paper summarizes the current status of the ARROS development for fast reactor system applications at the KAERI.

\section{Development of Advanced ODS Steels}

\subsection{ODS Steel Composition}

Including Korea, various ODS steels as in-core structural materials for a SFR have been developed in Japan, Europe, USA, Russia, India and China. ODS steels have normally two kinds of phases, martensite and ferrite phases which are determined by containing amounts of ferrite and austenite former elements. These elements are well known to $\mathrm{Cr}, \mathrm{W}, \mathrm{Mo}, \mathrm{Ni}, \mathrm{V}, \mathrm{Mn}$ and $\mathrm{C}$ at a consolidation temperature of around $1150^{\circ} \mathrm{C}$. ODS ferritic steels usually contain a high $\mathrm{Cr}$ over $12 \mathrm{wt} \%$, resulting in an excellent compatibility with a coolant. ODS martensitic steel can have a lath martensitic structure and high dislocation density, which ensure better neutron irradiation resistance than ODS ferritic one. A martensite transformation also gives favorable isotropy in homogeneous microstructure and mechanical properties.

In KAERI, ARROS has been newly developed for the in-core structural components of a SFR. ARROS has been designed on the basis of a martensitic phase with consideration of the high homogeneity, productivity and reproducibility. $\mathrm{Cr}$ and Mo are the most important elements to determine the matrix phase of ODS steels. On the basis of the out-of-pile performance tests such as tensile and creep at $700^{\circ} \mathrm{C}$, microstructural observation and ion irradiation, the $\mathrm{Cr}$ and Mo contents were optimized to be $10 \%$ and $1 \%$, respectively. Our ODS steel containing $10 \% \mathrm{Cr}$ has a typical tempered martensitic structure with fine needle-like grains and grain boundary carbides. The addition of solid-solution hardening elements such as Mo usually acts to the improvement of strength. However, an excessive addition of Mo leads to form the brittle phase, called as Laves phase on the prior austenite grain and lath boundaries as well as the coarsened carbides under high-temperature stress conditions exposed to a neutron irradiation environment. Therefore, the content of Mo was controlled to be $1 \mathrm{wt} \%$ to enhance the long-term creep property in ARROS. Several minor alloying elements such as $\mathrm{Mn}$, Ti, and V could also be added to improve the various characteristics of ARROS. Mn could serve to increase the strength of a matrix by the martensitic strengthening as austenite-forming elements and contents could be 0.01 to $1 \mathrm{wt} \%$ for Mn. Previous works on the chemical compositions of oxide particle in ODS steels showed that the addition of a small amount of Ti resulted in decreasing the particle size and increasing the number density and consequently improving the high temperature creep strength.

\subsection{Fabrication Technology Development of ODS Steel Tube}

The cladding tube of a SFR which is being developed at the KAERI is dimensioned to be $7.4 \mathrm{~mm}$ in outer diameter, $0.54 \mathrm{~mm}$ in wall thickness and $2500 \mathrm{~mm}$ in length. The ARROS tubes were fabricated by pre-alloyed powder fabrication, mechanical alloying, hot consolidation and tubing processes. Pre-alloyed powders without $\mathrm{Y}_{2} \mathrm{O}_{3}$ were fabricated by an atomizing process. Pre-alloyed powders and $\mathrm{Y}_{2} \mathrm{O}_{3}$ powder were mechanically alloyed using a high energy horizontal ball-mill apparatus (Model: Simoloyer CM-20). A modified mechanical alloying condition has been developed in ARROS. Continuous operation with low and high collision energy between raw powders and grinding media is a key technology. This process was successfully applied to fabricate mechanical alloying powders with very fine and homogeneous particles.

Mechanically alloyed powders were then charged in a steel capsule, and degassed at $500^{\circ} \mathrm{C}$ for 1 hour. All powder handling processes for the weighing, collecting, sieving, and charging were conducted in a completely controlled high purity argon atmosphere to prevent oxygen contamination during the process. After a pre-heating in the furnace at $1100^{\circ} \mathrm{C}$ for 2 hours, the capsules were extruded with a 6.4:1 extrusion ratio. After a heat treatment at $1100^{\circ} \mathrm{C}$ for 1 hour followed by a furnace cooling, advanced radiation resistant ODS steel showed a hardness of about $250 \mathrm{Hv}$, which was a sufficient hardness level for the tubing including pilgering and the colddrawing process. On the basis of this heat treatment condition, the ODS steel tube could be fabricated.

\subsection{Joining Technology Development of ODS Steel Tube}

Joining between ODS steel and other structural materials are one of the important processes for the structural components in a SFR system. Fuel cladding assemblies for a SFR are designed to be fabricated by joining be- 
tween the cladding tube and end-plug. For application of ODS steel to these structural components, reliable joining techniques should be developed with such a process in which the microstructures with a homogeneous distribution of nano-scaled oxide particles are not remarkably changed by the joining process. Several solid-state joining techniques have been developed for joining of ODS steel with F/M steel, such as diffusion bonding, friction stir welding (FSW), and magnetic pulse welding (MPW).

The diffusion bonding was studied to join between ODS and F/M steels under uniaxial pressing loads [4]. The phase transformation during the bonding process was utilized to eliminate the residual bonding interface by the grain boundary migration. The sample has a dual-phase grain structure consisting of tempered martensite with fine equiaxed grains and elongated ferrite. After a bonding process at $1150^{\circ} \mathrm{C}$ for 1 hour under the uniaxial load of $15 \mathrm{MPa}$ following furnace cooling with a cooling rate of $5^{\circ} \mathrm{C} / \mathrm{min}$, very large grains were observed. Relatively large grains were determined to be ferrite phase formed through a phase transformation from austenite to ferrite by a diffusional transformation during the cooling stage. Due to the phase transformation, the diffusion bonding interface was migrated and could not distinguish between two base materials even though the bonding boundary was actually located at the center of the bonding structure. To initiate the microstructure of diffusion bonded jone, post bonding heat treatments were applied. As a result, fine oxide particles of the diffusion joint region appeared to be homogeneously distributed in the matrix, which shows no difference with the results in the base metal. This result indicates that the diffusion bonding between ODS and FM steels with the phase transformation makes a favorable joint without a residual bonding interface or defects.

FSW is considered to be one of the promising welding technique for ODS steels as the technique helps in retaining the homogeneous nano-oxide particle distributions in the matrix [5]. The mechanical properties of the FSW joints are found to be superior to that of the base alloy. The diameter of the FSW tool should be reduced to 3 - $5 \mathrm{~mm}$ for the FSW of the end plug with the clad tube. In this case, the frictional heat generated may not be sufficient because of the small frictional volume. The ODS and F/M steels are expected to be used as the cladding tube and end-plug, respectively. The outer diameter of the tube is $7.4 \mathrm{~mm}$, and the wall thickness is $0.54 \mathrm{~mm}$. After the nuclear fuel is loaded, the end-plug and tube have to be joined using a solid-state method to avoid a possible reaction from nuclear fuel. Relatively sound welds were made with a tool traveling speed of $90 \mathrm{~mm} / \mathrm{min}$ and rotating speed of $1500 \mathrm{rpm}$. The same tool rotation and traveling speed were effective for joining both and evenly mixed material flows are observed. No voiding or cracks could be found in the weld zones. The FSW tool was made of Inconel 718, and the diameter of tool was $3.5 \mathrm{~mm}$. The rotation speed of tool and jig were $1200 \mathrm{rpm}$ and $1.5 \mathrm{rpm}$, respectively. It was found that the FSW was very successful for the joining of the tube and end-plug, and the joint showed defect free and regular surface. After the successful joining, the burst test of the joint was performed by means of blowing Ar gas inside the tube.

MPW technique is also considered to be one of strong candidate joining technique of ODS steel tube. MPW is a solid-state impact joining method, which uses the power of a high-energy magnetic field to accelerate a metal piece onto another stationary one and to create a metallic bonding. Considerable progress on the MPW technique has been made [6]. It is expected that MPW technique can be applied to the joining of ODS steel cladding tube to the end plug for a SFR application.

\section{Summary}

The ODS steels are being considered as the most prospective candidate materials of in-core structural components such as cladding tubes in a SFR. ARROS (10Cr-1Mo ODS steels) with superior tensile and creep strengths at $700^{\circ} \mathrm{C}$ has been developed at the KAERI. Considerable progress on the fabrication and joining technologies of ODS steels has also been made. It is expected that ARROS will be used as in-core structural components of a commercial SFR in the future.

\section{Acknowledgements}

This work was supported by the National Research Foundation of Korea (NRF) grant funded by the Korea government (MSIP) (No. 2015M2A8A4001839).

\section{References}

[1] Kim, T.K. and Kim, S.H. (2011) Study on the Cold Working Process for FM Steel Cladding Tubes. Journal of Nuclear Materials, 411, 208-212. http://dx.doi.org/10.1016/j.jnucmat.2011.02.017 
[2] Noh, S. Choi, B.K., Kang, S.H. and Kim, T.K. (2014) Influence of Mechanical Alloying Atmospheres on the Microstructures and Mechanical Properties of 15Cr ODS Steels. Nuclear Engineering and Technology, 46, 857-862. http://dx.doi.org/10.5516/NET.07.2013.096

[3] Mao, X., Kim, T.K., Kim, S.S., Han, Y.S., Oh, K.H. and Jang, J. (2015) Crystallographic Relationship of YTaO $\mathrm{Par}^{-}$ ticles with Matrix in Ta-Containing 12Cr ODS Steel. Journal of Nuclear Materials, 461, 329-335. http://dx.doi.org/10.1016/j.jnucmat.2015.03.018

[4] Noh, S., Kimura, A. and Kim, T.K. (2014) Diffusion Bonding of 9Cr ODS Ferritic/Martensitic Steel with a Phase Transformation. Fusion Engineering and Design, 89, 1746-1750. http://dx.doi.org/10.1016/j.fusengdes.2013.12.023

[5] Jeong, Y.H., Kim, W.J., Kim, D.J., Jang, J., Kang, S.H., Chun, Y.B. and Kim, T.K. (2014) Development of Advanced Structural Materials for Future Nuclear Systems in Korea. Procedia Engineering, 86, 1-7. http://dx.doi.org/10.1016/j.proeng.2014.11.004

[6] Lee, J.G., Park, J.J., Lee, M.K., Rhee, C.K., Kim, T.K., Spirin, A., Krutikov, V. and Paranin, S. (2015) End Closure Joining of Ferritic-Martensitic and Oxide-Dispersion Strengthened Steel Cladding Tubes by Magnetic Pulse Welding. Metallurgical and Materials Transactions A, 46A, 3132-3139. http://dx.doi.org/10.1007/s116601-015-2905-5 